\title{
Echocardiographic Short-Term Follow up of Children after Transcatheter Closure of Patent Ductus Arteriosus
}

\author{
Ahmed R. Afifi ${ }^{\text {a }}$, Sahar A. El-Shedoudy ${ }^{\text {b }}$, Mohammed A. El-Baz ${ }^{\text {a }}$, Hesham A. El-Ghaiaty ${ }^{\text {a }}$
}

\section{a Department of pediatrics, Benha faculty of medicine, Benha University, Egypt. b Department of cardiology, Tanta faculty of medicine, Egypt. \\ Correspondence to: Ahmed R. Afifi, Department of pediatrics, Benha faculty of medicine, Benha University, Egypt \\ Email:}

ahmed.sanad86@fmed.bu.edu.eg

Received: 19 November 2019

Accepted: 14 July 2020

\begin{abstract}
:
Background: Patent ductus arteriosus constitutes 5-10\% of all the congenital heart diseases. Volume overloading of the left side of the heart, risks of endocarditis, aneurysm of patent ductus arteriosus (PDA), and pulmonary vascular disease are indications for closure of the defect. Purpose: Evaluation of the efficacy and safety of PDA device closure in the paediatric age group patients. Methods: This prospective observational study included 26 children with a mean age of $30.2 \pm 27.6$ months and a mean weight of $12.8 \pm 6.6 \mathrm{~kg}$. Echocardiographic follow up was done at 24 hour, 1 week and 3 months post-intervention. Evaluation included assessment of residual shunt, left ventricle dimensions, left atrium/aorta ratio and velocity along descending aorta and left pulmonary artery. Results: Three different devices were used; the Amplatzer duct occluder (ADO-I) and its delivery system, PFM Nit-Occlud and Nit-Occlud PDA-R. All the patients were discharged safely from hospital after 24 hours of admission. Complete ductus closure was achieved in $77 \%$ of cases by 24 hours post-intervention, and in $96.15 \%$ after three months. The left ventricular end diastolic diameter (LVEDd) Z score decreased
\end{abstract} from $2.13 \pm 2.37$ pre-intervention, to $0.65 \pm 1.8$ after 3 months $(p<0.001)$ while LA/AO ratio decreased from $1.36 \pm 0.30$ pre-intervention to $1.13 \pm 0.15$ after 3 months $(p<0.001)$. Although the LV showed decrease in systolic function (FS), all the patients showed improvement in symptoms. No significant obstruction along the descending aorta or left pulmonary artery was reported. No complications like thrombus formation, blood loss or infective endocarditis, in any case, were reported.

Conclusion: Trans-catheter closure of PDA is effective and safe with rapid reversal of the left sided overload. Similar studies with long term follow up are needed for further evaluation of the LV systolic function pattern.

Key Words: PDA, device closure, trans-catheter, echocardiographic, short term. 


\section{Introduction}

Patent ductus arteriosus constitutes $5-10 \%$ of all the congenital heart diseases. Volume overloading of the left side of the heart, risks of endocarditis, aneurysm of PDA, and pulmonary vascular disease are indications for closure of the defect (1). Surgical ligation was first reported in 1939 by Gross (2). Within few decades, PDA was the first example of congenital heart disease to be treated by transcatheter closure by Porstman et al. in 1967 (3). Many devices were used through the last decades. Pharmacological closure of PDA can be done in premature infants using indomethacin and ibuprofen (4).

\section{Aim of the work}

This study was carried out to evaluate the short-term hemodynamic effect on the left side of the heart after trans-catheter PDA closure using different devices in the paediatric age group.

\section{Patients and Methods}

All procedures performed in studies involving human participants were in accordance with the ethical standards of the institutional research committee and with the 1964 Helsinki declaration and its later amendments or comparable ethical standards. This article does not contain any studies with animals performed by any of the authors.

This is a prospective observational study that included 26 patients of the paediatric age groups who were previously diagnosed to have PDA and suitable for per-cutaneous trans-catheter closure. They were selected from Tanta \& Benha University Hospitals during the period from December 2012 to December 2014.

All the studied cases were subjected to thorough history taking, thorough clinical examination and Two-dimensional and Doppler Echocardiography. Transthoracic echocardiography was done evaluating the diameter of pulmonary end of the ductus arteriosus, left atrium to aorta ratio and left ventricular end diastolic dimensions ( $\mathrm{Z}$ score).

After the procedure, follow up color-doppler ultrasound was used to detect and quantify any residual shunt. Doppler ultrasound was used to determine flow and velocity patterns in the descending aorta and left pulmonary artery to rule out obstruction. M-mode echocardiography with estimation of the left atrium to aorta ratio and left ventricular end diastolic dimension ( $\mathrm{Z}$ score) was done comparing the results with that before the procedure.

All the procedures were performed under general anaesthesia. Heparin in a dose of 50100 IU/ kg body weight and parenteral antibiotics were given to all the patients. 
Femoral venous and arterial accesses were right anterior oblique (RAO) and straight lateral views were performed to take the measurement of the narrowest ductal diameter, size of ampulla and length of ductus.

All the devices included in the study (Amplatzer devices, Nit-Occlude PFM and Nit-Occlud® PDA-R ) were deployed using the ante-grade approach as in the manufacturers' instructions (5). Descending aortography was performed after device/coil placement, to document residual shunts, and left pulmonary artery or aortic obstruction.

Once optimal position was confirmed, the device/coil was released. Again, aortography was performed 10 minutes later to evaluate the presence of any residual shunt. A complete two dimensional and color-doppler echocardiographic studies were performed on all the patients at $24 \mathrm{hrs}, 1$ week and at 3 months post-procedure.

Special attention was paid to residual ductal flow, left pulmonary artery or aortic stenosis, left atrium/aorta ratio and left ventricular dimension $\mathrm{Z}$ scores. The online tool parameter (Z) was used to calculate the $\mathrm{Z}$ score of the LV.

\section{Results}

The age of the studied cases ranged from 6 to 108 months (9 years) with a mean of $30.2 \pm$ 27.6 months. Their weights ranged from 6 to established. Aortic arch angiography in $30^{\circ}$ $33 \mathrm{~kg}$ with a mean of $12.8 \pm 6.6 \mathrm{~kg}$. Their height ranged from 65 to $134 \mathrm{~cm}$ with a mean of $85.4 \pm 18.8 \mathrm{~cm}$ and their body surface areas ranged from 0.347 to $1.07 \mathrm{~m}^{2}$ with a mean of $0.54 \pm 0.2 \mathrm{~m}^{2}$. Female to male ratio was $4: 1$. The measurements are presented, with respect to body surface area, as tables with mean and SD values in table 1 .

Three different device types were used; Amplatzer duct occluder (ADO- I) in 18 patients $(69.3 \%)$, PFM Nit-Occlud in six patients $(23 \%)$ while Nit-Occlud PDA-R was used in two patients $(7.7 \%)$. Complete PDA occlusion was detected within 10 minutes post deployment in 16 patients (61.538\%), demonstrated by aortography, and after 24 hours post-intervention, in $77 \%$, and after 3 months in $96.15 \%$ (figure 1). No patients had absent femoral pulsation or needed blood transfusion. All the patients were discharged safely from hospital after 24 hours.

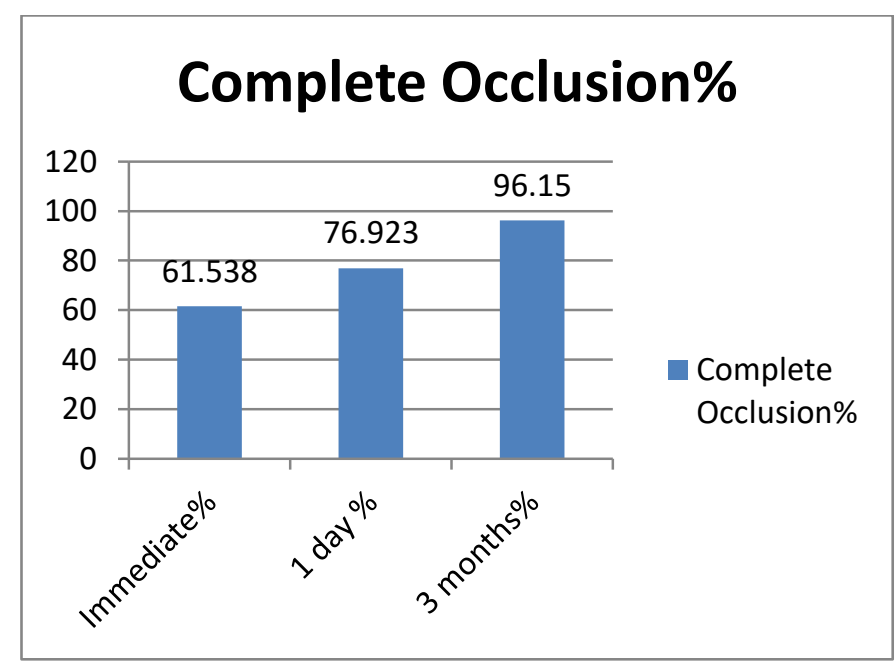

Figure1. Incidence of PDA complete occlusion after the procedure 
The mean peak velocity of left pulmonary artery slightly increased from $1.28 \pm 0.19 \mathrm{~m} / \mathrm{s}$ preintervention to $1.47 \pm 0.27 \mathrm{~m} / \mathrm{s}$ at one week, with further slight increase at 3 months $1.5 \pm 0.26 \mathrm{~m} / \mathrm{s}$ which was not significant. The maximum LPA velocity we recorded was 1.85 $\mathrm{m} / \mathrm{s}$ in one case $(3.8 \%)$.
As well, in the current study, there was no reported aortic obstruction as the maximum peak velocity recorded over the descending aorta was $1.7 \mathrm{~m} / \mathrm{s}$ in one case. The mean peak velocity over the descending aorta slightly increased from $1.31 \mathrm{~m} / \mathrm{s}$ pre-intervention to $1.39 \mathrm{~m} / \mathrm{s}$ at one week and $1.41 \mathrm{~m} / \mathrm{s}$ at 3 months post intervention.

Table (1): Data obtained by echocardiography before catheterization represented by mean \pm SD and range

\begin{tabular}{lll}
\hline \multicolumn{1}{c}{ Items } & Mean \pm SD & Range \\
\hline Duct diameter (Pulm. End) (mm) & $3.58 \pm 1.031$ & $1.3-6$ \\
LA/AO & $1.36 \pm 0.30$ & $1-1.8$ \\
LVEDd (Z score) & $2.13 \pm 2.37$ & $-0.57-9.72$ \\
FS \% & $37.18 \pm 5.097$ & $28-47$ \\
LPA velocity (m/s) & $1.28 \pm 0.18$ & $1.2-2.2$ \\
Descending AO velocity (m/s) & $1.31 \pm 0.15$ & $1.13-1.64$ \\
\hline
\end{tabular}

Increased LA/AO ratio was evident in 12 patients $(46 \%)$ with a mean of $1.63 \pm 0.19$. The LVEDd $\mathrm{Z}$ score was increased in 11 patients $(42.3 \%)$ with a mean of $2.13 \pm 2.37 \mathrm{Z}$ score. $\mathrm{LA} / \mathrm{Ao}=$ left atrium/aorta, $\mathrm{LVEDd}=$ left ventricle end diastolic dimension, $\mathrm{FS}=$ fractional shortening, LPA= left pulmonary artery.

Table (2): Comparison between echocardiographic data pre catheterization, at one week and 3 months after PDA closure

\begin{tabular}{ccccccc}
\hline Item & Pre closure & After 1week & After 3months & & \multicolumn{2}{c}{ P-value } \\
& Mean \pm SD & Mean \pm SD & Mean \pm SD & P1 & P2 & P3 \\
\hline LA/AO ratio & $1.36 \pm 0.30$ & $1.251 \pm 0.2$ & $1.133 \pm 0.158$ & $<0.001$ & $<0.001$ & $<0.001$ \\
LVEDd (Z score) & $2.13 \pm 2.37$ & $0.43 \pm 2.3$ & $-0.65 \pm 1.8$ & $<0.001$ & $<0.001$ & $<0.001$ \\
FS \% & $37.18 \pm 5.0$ & $34.746 \pm 5.7$ & $31.51 \pm 5.44$ & $<0.001$ & $<0.001$ & $<0.001$ \\
\hline
\end{tabular}

$\mathrm{FS}=$ fractional shortening, $\mathrm{LA} / \mathrm{Ao}=$ left atrium/aorta, $\mathrm{LVEDd}=$ left ventricle end diastolic dimension

\section{Discussion}

First transcatheter method was developed by Porstman et al. in late 1960s, followed by Rashkind et al in late 1970s (6) and these paved the way for the development of a number of other PDA closure devices. Over the last 4 decades, many techniques and devices have been used for patent ductus arteriosus (PDA) occlusion. 
Interventionalists in the United States commonly use the Amplatzer Duct Occluder (ADO, AGA Med Corp, MN) and those in Europe use the ADO or the Nit- Occlud Coils (PFM Medical, Germany) (3).

In our study, immediate complete PDA occlusion within 10 minutes post deployment aortography was achieved in 16 patients $(61.538 \%)$. Trivial residual flow to the left pulmonary artery was seen in 4 patients $(15.3 \%)$. Foaming in the device was noticed in 6 patients $(23 \%)$. At 24 hours follow up by echocardiography, 20 patients $(76.923 \%)$ had complete closure while $96.15 \%$ of cases had completely closed PDA at three months follow up echocardiography. Review of the results of ADO occlusion in a study showed small to trivial shunts in $17 \%$ of cases by angiography immediately after implantation and decreased to $11 \%$ by echocardiography after 24 hours.

At one-month follow-up, $1 \%$ had trivial residual shunts and none at 6-month followup (7). In a multicenter USA trial using the ADO device, complete angiographic occlusion was shown in $76 \%$ of the patients immediately after implantation, which increased further to $89 \%$ on the following day by echo-doppler studies. Complete closure was demonstrated in $99.7 \%$ of the patients at one year follow-up (10).
No patients had absent femoral pulsation and no patients needed blood transfusion. All the patients were discharged safely from hospital after 24 hours admission. This short hospital stay is one of the advantages of transcatheter PDA closure over the surgical ligation.

As regards the left atrial dilatation assessed by M-mode echocardiography as a reflection of the volume overload of the PDA on the heart, there was a regression of this dilatation on follow up at one week, and three months. LA/AO ratio decreased from 1.36 to 1.25 at one week, and further decrease to 1.13 was achieved at 3 months after successful ductal closure.

The mean left ventricular end diastolic diameter (LVEDd) Z score decreased from $2.13 \pm 2.37$ pre-intervention, to $0.43 \pm 2.3$ at one week and to $-0.65 \pm 1.8$ at 3 -month follow up. This is similar to the findings of another study (8), that showed that LV end diastolic dimensions also decreased significantly after successful PDA closure; the mean LVED decreased from $40 \pm 9$ before PDA closure to $36 \pm 6 \mathrm{~mm}$ one month after closure.

With Doppler echocardiography, we compared the peak velocities recorded in left pulmonary artery and descending aorta preintervention and that at one week and 3 months to detect any obstruction related to the occlusion device. No reported partial left 
pulmonary artery (LPA) obstruction. The mean peak velocity of the left pulmonary artery slightly increased from $1.28 \pm 0.18 \mathrm{~m} / \mathrm{s}$ preintervention to $1.47 \pm 0.27 \mathrm{~m} / \mathrm{s}$ at one week, with further slight increase at 3 months $(1.50 \pm 0.26)$. The maximum LPA velocity we recorded was $1.85 \mathrm{~m} / \mathrm{s}$ in one case $(3.8 \%)$. Left pulmonary artery stenosis due to protrusion of the device into the proximal left pulmonary artery has rarely been observed in infants and smaller children (9). Another study (10) reported two cases of partial obstruction of the LPA seen on follow up $(2.7 \mathrm{~m} / \mathrm{s}$ on echocardiography).

Aortic obstruction is a concerning complication of transcatheter PDA closure using ADO. In most patients, obstructions were clinically insignificant, detected only by Doppler echocardiography. Furthermore, blood flow velocities decreased during follow-up (10). Rarely, significant obstructions were observed in smaller infants with larger PDA, and a device removal was necessary in these patients (11).

In the current study, no reported aortic obstruction as the maximum peak velocity recorded over the descending aorta was 1.7 $\mathrm{m} / \mathrm{s}$ in one case. The mean peak velocity over the descending aorta slightly increased from $1.31 \mathrm{~m} / \mathrm{s}$ pre-intervention to $1.39 \mathrm{~m} / \mathrm{s}$ at one week and $1.41 \mathrm{~m} / \mathrm{s}$ at 3 months postintervention.
In the current study, there was no reported thrombus formation, thromboembolism or infective endocarditis in any case after successful ducat closure. Prophylaxis for infective endocarditis is recommended for 6 months in all patients (12).

\section{Conclusion and summary}

Transcatheter closure of PDA in infants and children is a feasible and effective modality of treatment with excellent results, and thus it should be the treatment of choice in infants and children. The hemodynamic effects of PDA shunting regress rapidly after ductus closure with significant decreases in the left sided overload indices. 2D echocardiography is a useful tool for follow up after PDA closure. Similar studies with long term follow up are needed for further evaluation of the LV systolic function pattern.

\section{References}

1. Al-Hamash SM, Wahab HA, Khalid ZH and Nasser IV (2012). Transcatheter closure of patent ductus arteriosus using ado device: retrospective study of 149 patients. Heart Views;13(1):1-6.

2. Alexi-Meskishvili VV and Bottcher W (2010). The first closure of the persistent ductus arteriosus. Ann Thorac Surg. 90(1):349-56.

3.Ghasemi A, Pandya S, Reddy SV, Turner DR, Du W, Navabi MA, et al (2010). Trans-catheter closure of patent ductus arteriosus-What is the best device? Catheter Cardiovasc Interv. 76(5):687-95.

4.Yang EM, Song ES and Choi YY (2013). Comparison of oral Ibuprofen and intravenous indomethacin for the treatment of patent ductus 
arteriosus in extremely low birth weight infants. J Pediatr (Rio J). 89(1):33-9.

5.Peirone A, Diaz J, Contreras A, Banille E, Cabrera M, Spillmann A, et al (2011). Percutaneous closure of the patent ductus arteriosus using the Nit-Occlud PDA$\mathrm{R}$ (reverse) device: initial experience reporting immediate and short-term results. J Invasive Cardiol. 23(12):513-6.

6.Rashkind WJ, Mullins CE, Hellenbrand WE and Tait MA (1987). Nonsurgical closure of patent ductus arteriosus: clinical application of the Rashkind PDA Occluder System. Circulation.75(3):583-92.

7.Doshi AR and Rao PS (2013). Development of aortic coarctation following device closure of patent ductus arteriosus. J Invasive Cardiol. 25(9):464-7.

8.Galal MO, Amin M, Hussein A, Kouatli A, Al-Ata J and Jamjoom A (2005). Left ventricular dysfunction after closure of large patent ductus arteriosus. Asian Cardiovasc Thorac Ann. 13(1):24-9.
9.Al-Ata J, Arfi AM, Hussain A, Kouatli AA and Jalal MO (2005). The efficacy and safety of the Amplatzer ductal occluder in young children and infants. Cardiol Young. 15(3):279-85.

10.Pass RH, Hijazi Z, Hsu DT, Lewis V and Hellenbrand WE (2004). Multicenter USA Amplatzer patent ductus arteriosus occlusion device trial: initial and one-year results. J Am Coll Cardiol. 44(3):513-9.

11.Park YA, Kim NK, Park SJ, Yun BS, Choi JY and Sul JH (2010). Clinical outcome of transcatheter closure of patent ductus arteriosus in small children weighing $10 \mathrm{~kg}$ or less. Korean J Pediatr. 53(12):10127.

12.Masura J, Tittel P, Gavora P and Podnar T (2006). Long-term outcome of transcatheter patent ductus arteriosus closure using Amplatzer duct occluders. Am Heart J. 151(3):755 e7- e10.

To cite this article: Ahmed R. Afifi , Sahar A. El-Shedoudy, Mohammed A. El-Baz, Hesham A. El-Ghaiaty. Echocardiographic Short-Term Follow up of Children after Transcatheter Closure of Patent Ductus Arteriosus, BMFJ 2020;37(3): 619-625, DOI: 10.21608/bmfj.2020.19815.1170 